\title{
Automated Size Recognition in Pediatric Emergencies Using Machine Learning and Augmented Reality: Within-Group Comparative Study
}

\author{
Michael Schmucker, BEng, MSc; Martin Haag, Dr sc hum \\ GECKO Institute, Heilbronn University of Applied Sciences, Heilbronn, Germany
}

\section{Corresponding Author:}

Michael Schmucker, BEng, MSc

GECKO Institute

Heilbronn University of Applied Sciences

Max-Planck-Str 39

Heilbronn, 74074

Germany

Phone: 491757581477

Email: michael.schmucker@hs-heilbronn.de

\begin{abstract}
Background: Pediatric emergencies involving children are rare events, and the experience of emergency physicians and the results of such emergencies are accordingly poor. Anatomical peculiarities and individual adjustments make treatment during pediatric emergency susceptible to error. Critical mistakes especially occur in the calculation of weight-based drug doses. Accordingly, the need for a ubiquitous assistance service that can, for example, automate dose calculation is high. However, few approaches exist due to the complexity of the problem.
\end{abstract}

Objective: Technically, an assistance service is possible, among other approaches, with an app that uses a depth camera that is integrated in smartphones or head-mounted displays to provide a 3D understanding of the environment. The goal of this study was to automate this technology as much as possible to develop and statistically evaluate an assistance service that does not have significantly worse measurement performance than an emergency ruler (the state of the art).

Methods: An assistance service was developed that uses machine learning to recognize patients and then automatically determines their size. Based on the size, the weight is automatically derived, and the dosages are calculated and presented to the physician. To evaluate the app, a small within-group design study was conducted with 17 children, who were each measured with the app installed on a smartphone with a built-in depth camera and a state-of-the-art emergency ruler.

Results: According to the statistical results (one-sample $t$ test; $P=.42 ; \alpha=.05$ ), there is no significant difference between the measurement performance of the app and an emergency ruler under the test conditions (indoor, daylight). The newly developed measurement method is thus not technically inferior to the established one in terms of accuracy.

Conclusions: An assistance service with an integrated augmented reality emergency ruler is technically possible, although some groundwork is still needed. The results of this study clear the way for further research, for example, usability testing.

(JMIR Form Res 2021;5(9):e28345) doi: 10.2196/28345

\section{KEYWORDS}

resuscitation; emergency medicine; mobile applications; mobile phone; user-computer interface; augmented reality; machine learning

\section{Introduction}

\section{Background}

The results in pediatric emergencies are not satisfactory. Too few children survive such emergencies with favorable neurological outcomes $[1,2]$. There are several reasons for this.
First, this type of emergency is very rare; in Germany, for example, there are only 1000 prehospital resuscitations for 30,000 emergency physicians per year, that is, on average, one emergency physician resuscitates a child every 30 years [3]. This observation deliberately ignores that there are specially trained pediatric emergency physicians in urban areas, as pediatric emergency physicians are not common. Second, 
emergency physicians find it difficult to remain calm in a child emergency. In a survey of 104 emergency physicians, conducted by Zink et al [4], 88\% said that they had already felt anxiety or excessive pressure at work. When asked for the reason, $84 \%$ said they had experienced these feelings in a pediatric emergency, followed by polytraumatized patients (20\%) and obstetric emergencies (18\%). Multiple answers were possible. Apart from the fact that the patient is a child and the psychological consequences that may result, it is mainly the anatomical differences between children and adults and the associated peculiarities of resuscitation that cause problems for emergency physicians. Although the resuscitation of an adult is quite standardized, there are individual differences in every child. The choice of using different processes as well as equipment is influenced by the size or weight of the child. For example, the size of the endotracheal tube and depth of insertion are specified [5] or the dosage of medication is calculated individually based on the patient's weight [6]. Especially in drug dosing, mistakes happen rather frequently, sometimes with life-threatening consequences [7-9]. This is because it is difficult to determine a child's weight and thus the correct dose. There are various methods to determine a child's weight. As Young and Korotzer [10] describe in their systematic analysis, the most precise method is parental estimation. If the parents are not present, the state of the art is to derive the weight from the height of the child using a so-called emergency ruler (eg, Broselow tape [6]). These tools are important, because the medics' estimations are not very accurate, according to the systematic analysis mentioned earlier [10]. Despite these aids, emergency physicians repeatedly express a desire for technical aids $[7,8]$. Therefore, one idea is to create a ubiquitous assistance service that uses modern wearables (eg, a smartwatch for measuring the compression depth [11], head-mounted displays [HMDs] as screens or for telemedical scenarios $[12,13]$ ) to provide a service that requires as little attention as possible while still providing great assistance (principle of calm technology [14]). To accomplish this, a high degree of automation must be achieved in addition to a high level of usability. The idea is to recognize the patient with computer vision algorithms and to be able to measure the patient directly using a depth camera. All other parameters can then be automatically derived, calculated, and displayed on an HMD, for example, as integrated into the process steps of the American Heart Association [15] or the European Resuscitation Council (ERC) [16] guidelines. After literature research, expert interviews, and initial research results [17], an app was programmed and evaluated using a comparative study to apply this level of automation.

\section{State of the Art}

There are several approaches to replace emergency rulers using technical support, for example, with a smartphone or a tablet [18-24]. Promising studies have already confirmed that the use of an app can minimize errors [22-24]. However, the problem with most apps (all mentioned earlier but one) is that there is no automation of size recognition, that is, manual entries are necessary. Apart from usability, there is also the problem that these values (age, weight, or height) must be known first. For inhospital cases, it can be assumed that the weight of the child is known; however, this does not apply to prehospital cases.
For some apps, even the now-obsolete age-based formula for calculating the dosages is used [18], which is inferior to the length-based method [10]. A very interesting app is Optisizer developed by Wetzel et al [21]. A $20 \times 20-\mathrm{cm}$ tag placed next to the child is used as a reference value for the size. A first clinical trial looks promising [21]. However, the tag must be at the same level as the child, and the measurement must always be taken at a $90^{\circ}$ angle. This is simply because a camera without additional sensor technology has no relationship to angle and depth, and therefore, an accurate calculation cannot be made automatically. A revised version of this app, which should solve this problem, is announced by the authors in the outlook [21].

The aim of this paper is therefore to fill this gap. An app is programmed and evaluated that uses augmented reality (AR) and a depth camera to provide a simple, fast, and safe way to automatically determine a child's weight and thus the medication dosage.

\section{Methods}

\section{Background}

The evaluated app is based on a prototype in which the measuring accuracy of the Asus ZenFone AR's depth cameras has already been proven [17]. This does not deviate significantly from the measurements made with the aid of an emergency ruler. However, the handling was problematic; the individual measuring points (head and foot of the child) had to be marked manually. To address this problem, the app was further developed so that it recognizes the child using machine learning and then performs an automated measurement. Furthermore, dosages for adrenalin and amiodarone are calculated and made available to the user. The calculations are based on the data of the KiGGS (Studie zur Gesundheit von Kindern und Jugendlichen in Deutschland [German Health Interview and Examination Survey for Children and Adolescents]) study of the Robert Koch Institute (RKI) [25] and the formulas stated in the ERC guidelines [16]. It must therefore be evaluated whether the new functionality of the app can repeat the good values of the previous study. The decisive factor here is how well the process of machine vision (recognition of the child, head to foot) and the size recognition work in combination.

\section{App Design and Technology}

The size recognition of a patient and the dose calculation basically consist of three steps. In the first step, a person is detected in the camera's field of view using an object recognition algorithm and is classified as a human being. In addition, the area in the image in which the child is located must be delimited as precisely as possible from the surroundings, and the measurement points (upper and lower limits) must be defined. In the second step, the distance between these two points and the camera is measured. This defines two points in 3D space, and the size can be calculated. In the final step, based on stored data, the respective dosages must be loaded and displayed.

\section{Object Recognition}

As soon as the app is started, it is ready to detect objects. The object detection is performed using the TensorFlow Object 
Detection API [26] and the TensorFlow Detection Model Zoo [27]. Based on different parameters, such as GitHub activity, Google searches, books, or job descriptions, it can be said that TensorFlow is the leading deep learning framework [28].

Recognizing people is one of the standard tasks of machine vision, so it should not be necessary to train the entire functionality from the beginning. To simplify the clarity of the app and to save resources, only the functionality for recognizing persons is activated. If a person is recognized, a bounding box is placed around this person and the confidence is displayed. With a confidence of $98 \%$ or more, the coordinates of the bounding box are stored in variables. The respective $y$-coordinates of two diagonally opposite points of the four corner points of the box indicate the size of the person.

\section{Size Measurement}

The size is measured using the Google Tango framework. Switching between the activities is done using the Intent class of Android. Tango is the predecessor of ARCore [29] and was developed for mobile phones with depth cameras. By default, Tango uses touch to set the measurement points manually. To automate this, the points from before are adopted. To prevent diagonal measurements, the $\mathrm{x}$ values of the two points are averaged and used as X-coordinates for both measuring points. It is important that both the object detection and the size measurement work with the same resolution (in this case, $1920 \times 1080$ pixels).

Figure 1. Schematic representation of the two measurements. $S_{1}$, measurement with the app; $S_{2}$, measurement with the emergency ruler.

\section{Measurement $\mathrm{S}_{1}$}

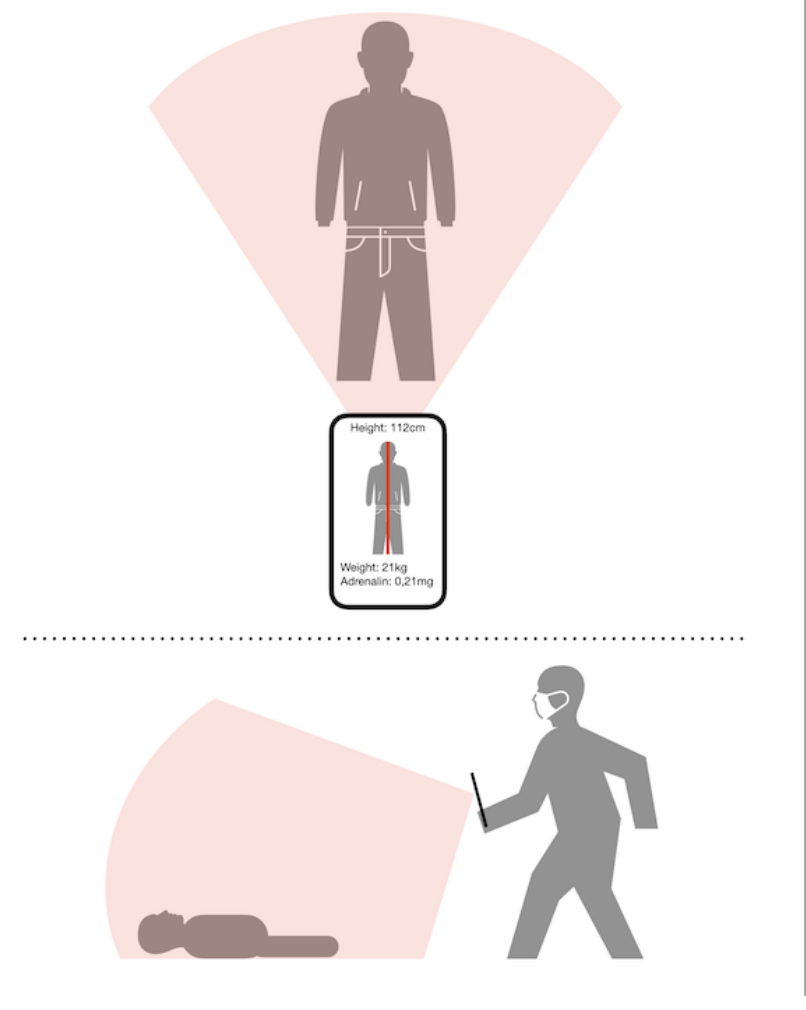

\section{Dose Calculation}

Depending on the size, the corresponding weight is loaded from a store and the appropriate dose is calculated and displayed using the formulas specified in the guidelines of the ERC [16]. The size to weight ratio is, as already mentioned, created using data from the KiGGS study of the RKI [25] and the formulas given in the guidelines of the ERC [26].

\section{Study Design and Measurements}

The study design was a within-group setting in which each of the children was anonymously measured first with the app, installed on a ZenFone AR, and then with an emergency ruler (Pediatape [30]). The measurements $\left(\mathrm{S}_{1}, \mathrm{~S}_{2}\right)$ were performed in a room of a kindergarten during daylight. The children were lying on a wooden floor. For the measurement with the app $\left(\mathrm{S}_{1}\right)$, the person taking the measurement stood in front of the child; the angle or the height of the camera was not specified. The process was similar to taking a photo with the smartphone. The only important factor was that the person being measured was captured as a whole by the camera (see Figure 1). When measuring with the emergency ruler $\left(\mathrm{S}_{2}\right)$, the beginning of the measurement was placed at the head and the size was then read at the foot (see Figure 1). For both measurements, it was important that the person did not curve their legs. The parameters of age, height, weight, and gender of the children were not known from the beginning and were therefore randomly selected. In conclusion, there was one independent variable (measuring device) that took two values (app, emergency ruler).

\section{Measurement $\mathrm{S}_{2}$}

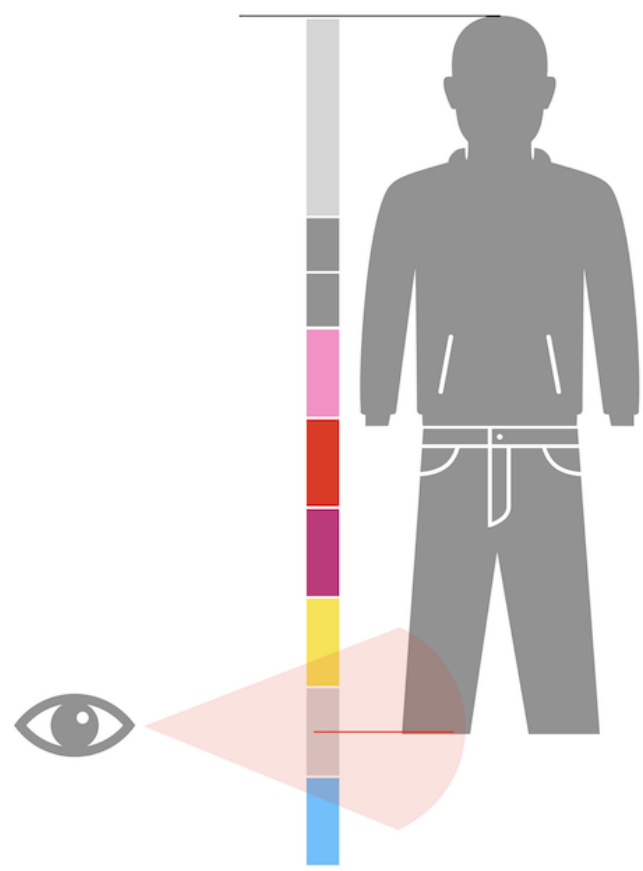




\section{Recruitment}

The study included 17 children from two kindergartens. Originally, over 50 parent letters were issued, but at the time of the study, only 17 permissions were obtained. There was no formal sample size calculation; the analysis plan was decided post hoc.

\section{Legal Aspects}

Because the measurements performed could not cause any definable harm, no ethics committee was consulted prior to the execution. A legal review of the app with regard to the Medical Devices Act is pending but is considered to be too early at this stage.

\section{Statistical Analysis}

\section{Shapiro-Wilk Test}

Because fewer than 30 subjects were available and we could not rely on the central limit theorem, which states that a sample is normally distributed when more than 30 samples are present, a Shapiro-Wilk test was performed prior to the statistical test selection to check for a normal distribution of the collected data.

\section{Descriptive Statistical Analysis}

To better understand the data before performing a statistical test, some descriptive statistics were calculated and plotted. These include the average of the respective measurements $\left(S_{1}\right.$, $\mathrm{S}_{2}$ ), the median, and the standard deviation. In addition, it was checked whether the expected high correlation between the related measurements and the expected correlation of the measurements with the corresponding weight of the children was actually present. Furthermore, the measured heights are presented with the corresponding weights.

\section{One-Sample t Test}

To test for a significant difference, a one-sample $t$ test comparing the mean deviation of the difference $\left(S_{1}-S_{2}\right)$ to the reference value zero was executed. Two measurements are identical if the difference of the individual measurements is zero. The following hypothesis was tested at the significance level $\alpha=.05$ :

$H_{0}:$ There is no difference between the augmented
reality application with automated size recognition
using machine vision on the ZenFone AR and the
Pediatape emergency ruler in the quality of the
measurements.

If there were substantial differences, the app would not be suitable to act as an automated AR emergency ruler.

\section{Bland-Altman Limits of Agreement}

For a better overview, the results were additionally presented graphically. For this purpose, the Bland-Altman plot was used $[31,32]$. Thereby, the differences (delta) $S_{1}-S_{2}$ of the individual measurements $\left(\mathrm{S}_{1}, \mathrm{~S}_{2}\right)$ were plotted against their mean $\left(\left(\mathrm{S}_{1}+\right.\right.$ $\left.\mathrm{S}_{2}\right) / 2$ ). This resulted in the following formula:

$$
s(x, y)=\left(\frac{s_{2}+s_{2}}{8},\left(s_{1}-s_{2}\right)\right)
$$

The upper and lower limits of agreement (LOA) are defined as $\bar{d} \pm 1.96 s$ at a significance level of $\alpha=.05$, where $\bar{d}$ represents the mean difference and $s$ the standard deviation of pairwise differences. If $95 \%$ of the measurements lie within the LOA, both methods can be considered interchangeable, that is, both methods are equally appropriate [32].

\section{Regression Analysis}

To exclude a proportional bias, a linear regression analysis was performed at the end with the dependent variable (the measurement difference) and the independent variable (the mean).

\section{Results}

Table 1 lists the measurements performed and the associated weight, sorted ascending by the height, measured with the app. If the height was somewhere between x. 3 and x.7, x.5 was used; otherwise, the nearest full centimeter was used. This level of ambiguity is not a problem in the tested use case. 
Table 1. Participants' characteristics.

\begin{tabular}{|c|c|c|c|}
\hline Participant no. & Height measured with the app $(\mathrm{cm})$ & Height measured with the emergency ruler $(\mathrm{cm})$ & Weight $(\mathrm{kg})$ \\
\hline 1 & 98 & 98 & 15.1 \\
\hline 2 & 98.5 & 97.5 & 15.3 \\
\hline 3 & 99 & 101 & 15.3 \\
\hline 4 & 99.5 & 98.5 & 15.4 \\
\hline 5 & 100 & 100 & 18.9 \\
\hline 6 & 101 & 105 & 20.2 \\
\hline 7 & 102 & 100 & 15.1 \\
\hline 8 & 104.5 & 105.5 & 19.4 \\
\hline 9 & 107 & 107 & 19.4 \\
\hline 10 & 111 & 113 & 21 \\
\hline 11 & 111.5 & 112.5 & 22.6 \\
\hline 12 & 112.5 & 113.5 & 21.5 \\
\hline 13 & 113.5 & 112.5 & 20.5 \\
\hline 14 & 113.5 & 116.5 & 23.1 \\
\hline 15 & 119 & 118 & 20.8 \\
\hline 16 & 119 & 117 & 23.1 \\
\hline 17 & 121 & 119 & 19.4 \\
\hline
\end{tabular}

\section{Shapiro-Wilk Test}

Due to the small sample size, before applying a $t$ test, it must be examined whether the sample is normally distributed. The difference $\left(S_{1}-S_{2}\right)$ and the mean $\left(\left(S_{1}+S_{2}\right) / 2\right)$ were tested. The test was carried out using SPSS (IBM Corporation).
As Table 2 shows, none of the $P$ values are smaller than the significance level $\alpha=.05$ ( $\left.P_{\text {diff }}=.38 ; P_{\text {mean }}=.06\right)$. It can therefore be assumed that the sample is normally distributed in terms of both difference and mean.

Table 2. Shapiro-Wilk test results.

\begin{tabular}{llll}
\hline & Statistic & $W$ & $P$ value \\
\hline Difference & .95 & 17 & .38 \\
Mean & .90 & 17 & .06 \\
\hline
\end{tabular}

\section{Descriptive Statistical Analysis}

Measured with the emergency ruler, the subjects are on average $\emptyset_{\mathrm{er}} \approx 108 \mathrm{~cm}$ tall with a median of $\tilde{\chi}_{\mathrm{er}}=107 \mathrm{~cm}$ and a standard deviation of $s_{\mathrm{er}}=7.88 \mathrm{~cm}$. The app comes to an average of $\emptyset_{\mathrm{app}} \approx 107.5 \mathrm{~cm}$, also with a median of $\tilde{x}_{\mathrm{app}}=107 \mathrm{~cm}$ and a standard deviation of $s_{\text {app }}=7.82 \mathrm{~cm}$ (see Table 3 ).
Table 4 and Figure 2 show a strong correlation between both measurements, as expected.

There is also a strong correlation between the measured heights $\left(\mathrm{S}_{1}, \mathrm{~S}_{2}\right)$ and the associated weights (Table 5, Table 6, and Figure 3).

Table 3. Descriptive statistics.

\begin{tabular}{llll}
\hline & $\varnothing(\mathrm{cm})$ & $\widetilde{\boldsymbol{X}}(\mathrm{cm})$ & $s(\mathrm{~cm})$ \\
\hline Emergency ruler & 108 & 107 & 7.88 \\
Augmented reality app & 107.5 & 107 & 7.82 \\
\hline
\end{tabular}


Table 4. Correlation analysis (Pearson $r$ and significance) between the measured heights using the app $\left(\mathrm{S}_{1}\right)$ and ruler $\left(\mathrm{S}_{2}\right)(\mathrm{N}=17)$.

\begin{tabular}{lll}
\hline Variable & Height measured by emergency ruler & Height measured by the app \\
\hline Height measured by emergency ruler & & .98 \\
$\quad r$ & 1 & $<.001^{\mathrm{b}}$ \\
$P$ value & $-^{\mathrm{a}}$ & 1 \\
Height measured by the app & .98 & - \\
$\quad r$ & $<.001^{\mathrm{b}}$ & \\
\hline
\end{tabular}

${ }^{\mathrm{a}}$ Not applicable.

${ }^{\mathrm{b}}$ The correlation is significant at a significance level of .05 (two-tailed).

Figure 2. Correlation between the measurements taken with the emergency ruler and the app.

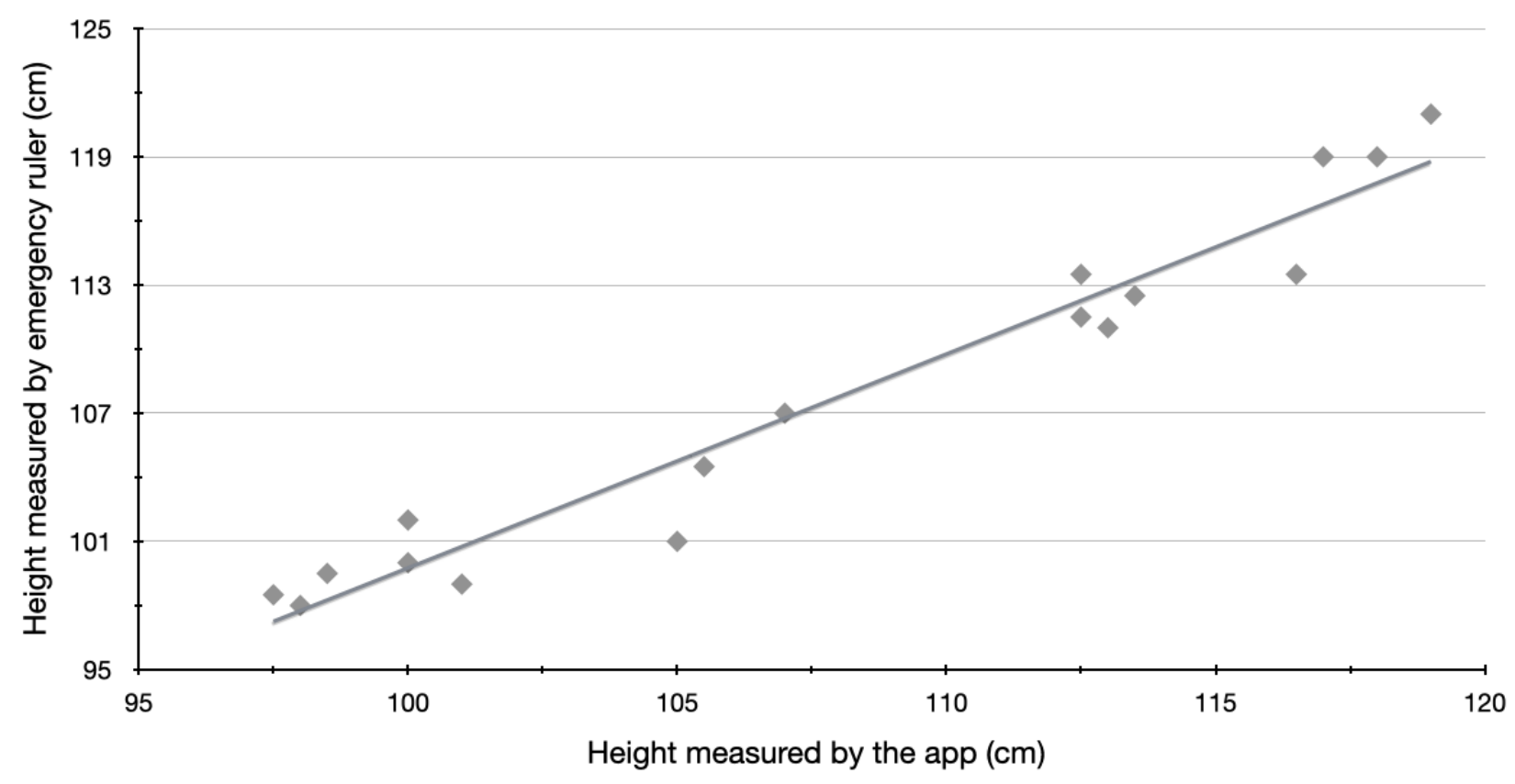

Table 5. Correlation analysis (Pearson $r$ and significance) between the measured height using the app and the weight.

\begin{tabular}{lll}
\hline Variable & Height measured by emergency ruler & Weight \\
\hline Height measured by emergency ruler & 1 & .85 \\
$\quad r$ & $--^{\mathrm{a}}$ & $<.001^{\mathrm{b}}$ \\
$\quad P$ value & & 1 \\
Weight & .85 & - \\
$\quad r$ & $<.001$ & 1 \\
\hline
\end{tabular}

${ }^{\mathrm{a}}$ Not applicable.

${ }^{\mathrm{b}}$ The correlation is significant at a significance level of .05 (two-tailed). 
Table 6. Correlation analysis (Pearson $r$ and significance) between the measured height using emergency ruler and the weight.

\begin{tabular}{lll}
\hline Variable & Height measured by emergency ruler & Weight \\
\hline Height measured by emergency ruler & 1 & .77 \\
$r$ & $--^{\mathrm{a}}$ & $<.001^{\mathrm{b}}$ \\
$P$ value & & 1 \\
Weight & .77 & - \\
$r$ & $<.001$ & \\
\hline value & & \\
\hline
\end{tabular}

${ }^{\mathrm{a}}$ Not applicable.

$\mathrm{b}^{\mathrm{T}}$ The correlation is significant at a significance level of .05 (two-tailed).

Figure 3. Correlation between both measured heights and the weight.

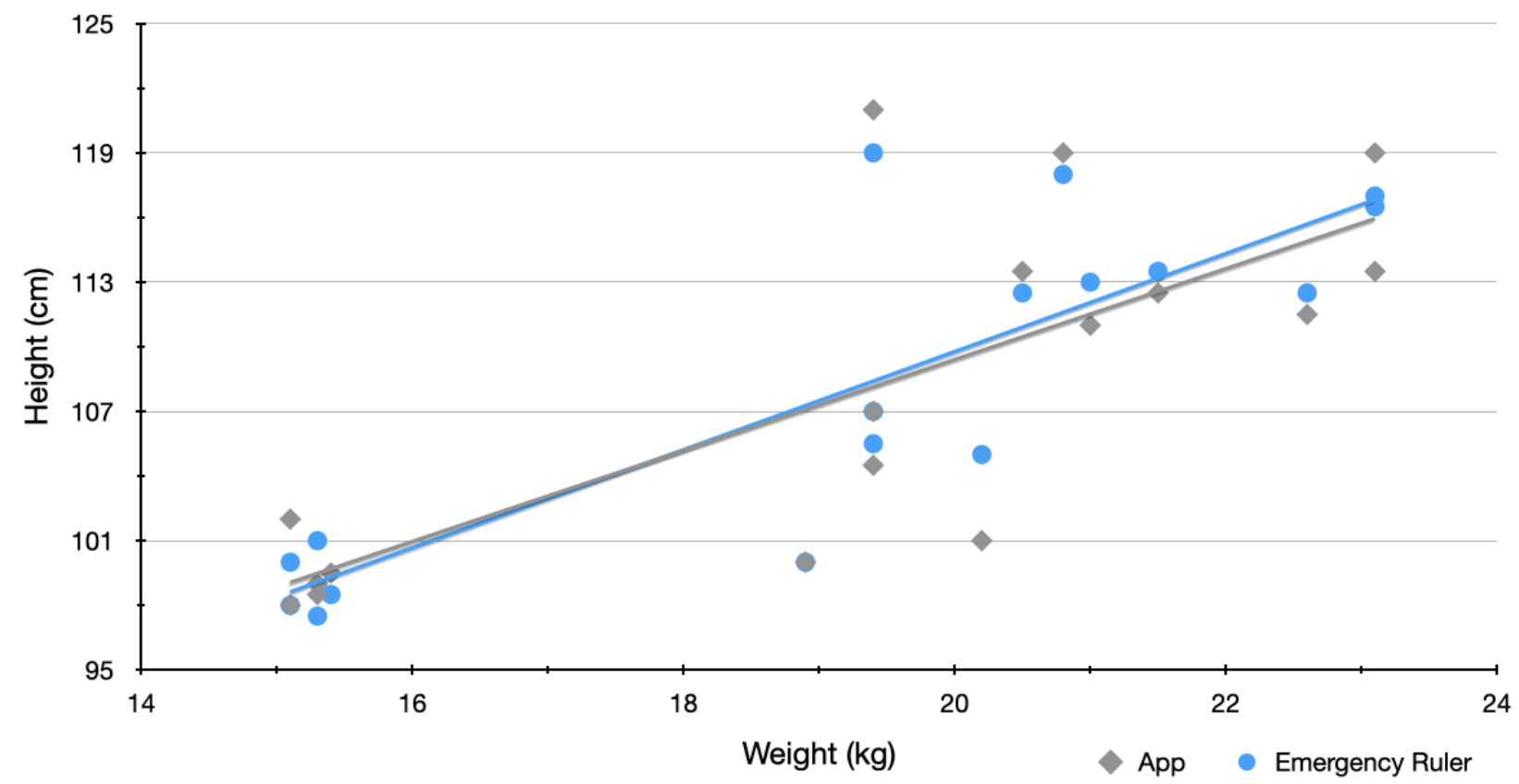

\section{One-Sample $t$ Test}

To determine a significant difference between the two measurements, a one-sample $t$ test of the measurement difference variable to the reference value zero was performed.

There was no significant difference in the measurement quality of the two measurements, according to the one-sample $t$ test $\left(\mathrm{t}_{16}=.82, P=.42\right.$; mean difference $.35,95 \% \mathrm{CI}-0.56$ to 1.26$)$. The delta value of the measurements was not significantly different from the reference value zero ( $\widetilde{\boldsymbol{x}}=.35, s=1.77$ ). $\mathrm{H}_{0}$ can thus be retained.

\section{Bland-Altman LOA}

In addition to the $t$ test, the results are presented with Bland-Altman LOA values to provide a better overview. As can be seen in Figure 4, at least $95 \%$ of the measurements lie between the upper and lower limits. Therefore, it can be said that there is no significant difference in the quality of the two measurements to the significance level $\alpha=.05$ and that both measurement methods are therefore interchangeable.

In most cases $(9 / 17,53 \%)$, there was a deviation of 0 to $1 \mathrm{~cm}$. In $14 / 17$ cases $(82 \%)$, the deviation was $2 \mathrm{~cm}$ or less. Deviations with more than $3 \mathrm{~cm}$ were rare $(1 / 17,6 \%)$. 
Figure 4. Bland-Altman plot.

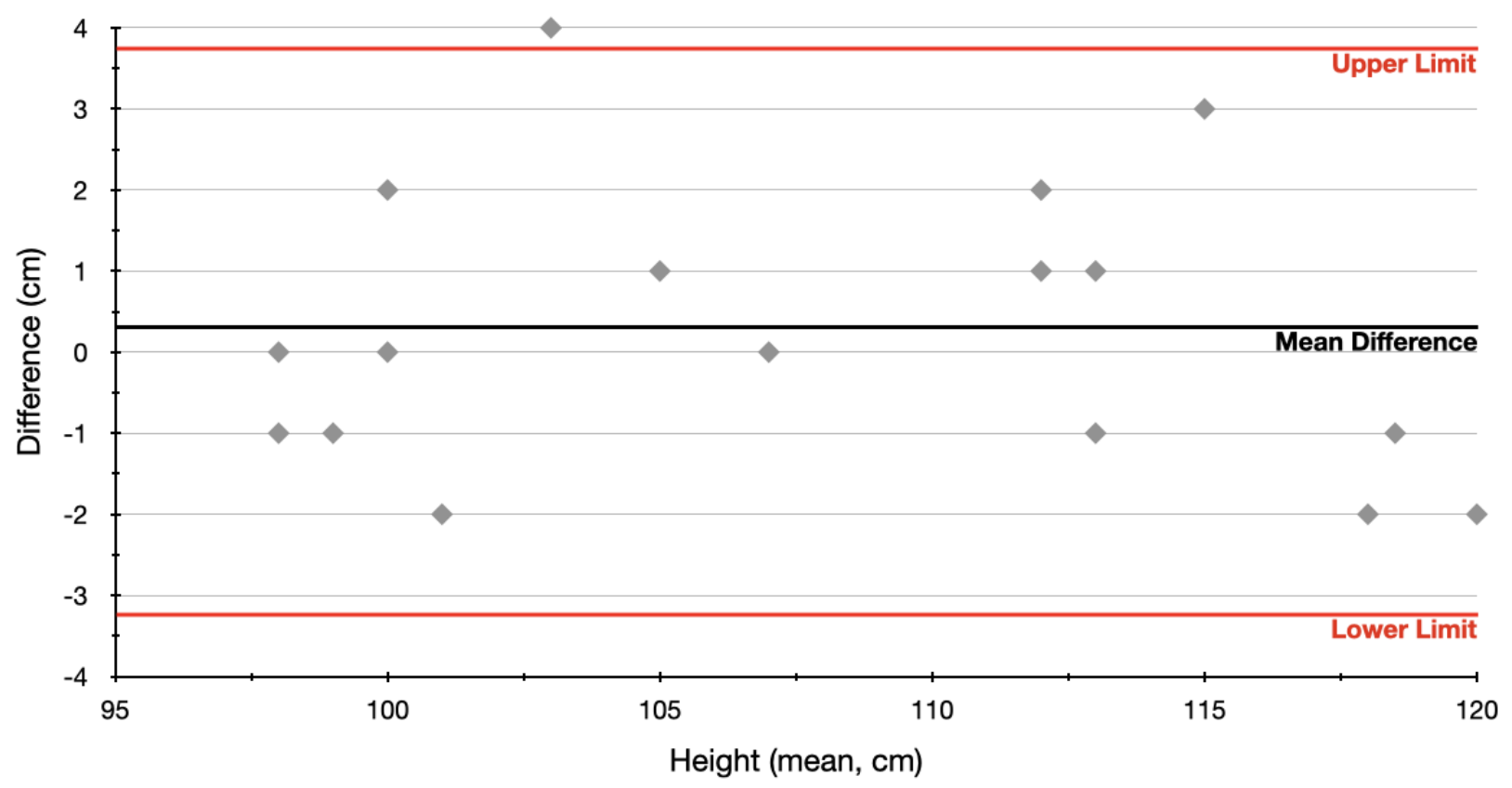

\section{Regression Analysis}

Table 7 shows no statistically significant result. The beta value for the mean is close to zero; the $t$ value is not significant. A proportional bias can be excluded. Thus, the app works the same regardless of the size of the children in the sample. For a better understanding, the regression line is plotted in Figure 5.

Table 7. Regression coefficients.

\begin{tabular}{|c|c|c|c|c|c|}
\hline \multirow[b]{2}{*}{ Model } & \multicolumn{2}{|c|}{ Unstandardized } & \multicolumn{3}{|c|}{ Standardized } \\
\hline & Beta & SE & Beta & $t(\mathrm{df})$ & $P$ value \\
\hline Constant & 3.18 & 6.33 & $\mathrm{~N} / \mathrm{A}^{\mathrm{a}}$ & $0.50(15)$ & .63 \\
\hline Mean & -0.03 & 0.06 & -0.12 & $-0.47(15)$ & .65 \\
\hline
\end{tabular}

${ }^{\mathrm{a}} \mathrm{N} / \mathrm{A}$ : not applicable. 
Figure 5. Regression line to exclude proportional bias.

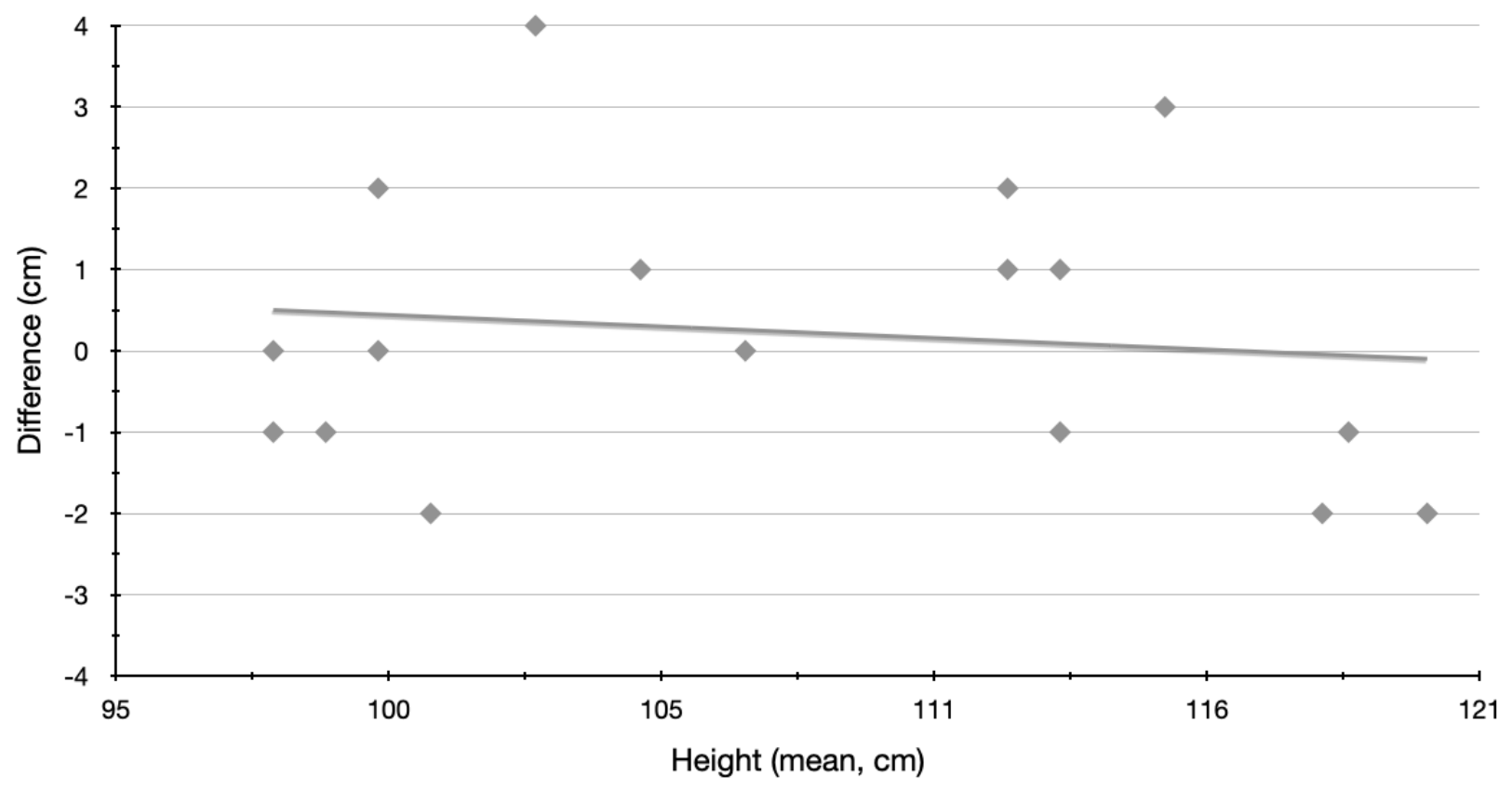

\section{Discussion}

According to this study, there is no significant difference in the quality of the measurements between a state-of-the-art emergency ruler and a smartphone with the newly developed app. The development of an assistance service including an AR emergency ruler is therefore technically possible. The $t$ test indicates no significant difference $\left(\mathrm{t}_{16}=.82 ; P=.42\right.$; mean difference $.35,95 \%$ CI -0.56 to 1.26$)$. As shown in Figure 4 , in more than half of the cases $(9 / 17,53 \%)$ the differences are $1 \mathrm{~cm}$ or less. The largest deviation is $4 \mathrm{~cm}$. The sample size is admittedly rather small, with 17 normally distributed samples, but the results suggest that the distribution will not change with larger sample sizes. For quality assurance purposes, only the weight was collected in addition to the two measurements. Age and gender were not included due to the principle of data minimization and the promised protection of anonymity. This means that it should not be necessary to calculate BMI retrospectively. Although this would be theoretically feasible, for the interpretation both age and gender are necessary in children [33]. Therefore, no classification of weight can be made. It should be further noted that the measurements were carried out in an indoor environment in daylight. Especially strong light or a bright background might affect the infrared camera. It should also be noted that Google discontinued its ambitious "Tango" project in 2018 [34], which was used for this app. Due to the additionally required expensive hardware (depth camera with infrared sensor), the Tango project could not become generally accepted. For AR game apps, it is not important how faultlessly objects are placed in space. Therefore, Google has decided on a type of technology that runs on almost all smartphones (ARCore). However, the Tango API is still available in Google Archive [35]. The latest trend in AR, however, is again moving toward depth sensing, as shown by Microsoft with the HoloLens [36], by Samsung with the Galaxy S20+ [37], or by Apple's new iPhone 12 Pro with light detection and ranging technology [38]. The extent to which these implementations are suitable for continuing this research needs to be evaluated. The long-term goal of this research is to create a ubiquitous pediatric emergency assistance service. An important step has been achieved with the automatic size recognition. At the moment, a study at a simulation center is planned to explore the usability aspects of the app under the most realistic conditions possible.

\section{Conflicts of Interest}

None declared.

\section{References}

1. Mick NW, Williams RJ. Pediatric cardiac arrest resuscitation. Emerg Med Clin North Am 2020 Nov;38(4):819-839. [doi: 10.1016/j.emc.2020.06.007] [Medline: 32981620]

2. Donoghue AJ, Nadkarni V, Berg RA, Osmond MH, Wells G, Nesbitt L, et al. Out-of-hospital pediatric cardiac arrest: an epidemiologic review and assessment of current knowledge. Ann Emerg Med 2005 Dec;46(6):512-522. [doi: 10.1016/j.annemergmed.2005.05.028] [Medline: 16308066] 
3. ÄrzteZeitung. Kinder-Notfälle. Die Angst fährt mit zum Einsatz. URL: https://www.aerztezeitung.de/Medizin/ Die-Angst-faehrt-mit-zum-Einsatz-235732.html [accessed 2021-05-04]

4. Zink W, Bernhard M, Keul W, Martin E, Völkl A, Gries A. Invasive Techniken in der Notfallmedizin. Anaesthesist 2004 Nov;53(11):1086-1092. [doi: 10.1007/s00101-004-0762-5]

5. Boensch M, Schick V, Spelten O, Hinkelbein J. Estimation of the optimal tube length: systematic review article on published formulae for infants and children. Article in German. Anaesthesist 2016 Feb;65(2):115-121. [doi: 10.1007/s00101-015-0123-6] [Medline: 26696266]

6. Schmidt AR, Haas T, Buehler KP, Ruetzler K, Weiss M, Schmitz A. Broselow®-Tape und Pädiatrisches Notfalllineal im Vergleich. Notfall Rettungsmed 2015 Sep 21;19(2):129-135. [doi: 10.1007/s10049-015-0070-4]

7. Kaufmann J, Laschat M, Wappler F. Medication errors in pediatric emergencies: a systematic analysis. Dtsch Arztebl Int 2012 Sep;109(38):609-616 [FREE Full text] [doi: 10.3238/arztebl.2012.0609] [Medline: 23093991]

8. Appelbaum N, Clarke J, Feather C, Franklin B, Sinha R, Pratt P, et al. Medication errors during simulated paediatric resuscitations: a prospective, observational human reliability analysis. BMJ Open 2019 Nov 25;9(11):e032686 [FREE Full text] [doi: 10.1136/bmjopen-2019-032686] [Medline: $\underline{31772103]}$

9. Hoyle JD, Davis AT, Putman KK, Trytko JA, Fales WD. Medication dosing errors in pediatric patients treated by emergency medical services. Prehosp Emerg Care 2012;16(1):59-66. [doi: 10.3109/10903127.2011.614043] [Medline: 21999707]

10. Young KD, Korotzer NC. Weight estimation methods in children: a systematic review. Ann Emerg Med 2016 Oct;68(4):441-451.e10. [doi: 10.1016/j.annemergmed.2016.02.043] [Medline: 27105839]

11. Gruenerbl A, Pirkl G, Monger E, Gobbi M, Lukowicz P. Smart-watch life saver: Smart-watch interactive-feedback system for improving bystander CPR. 2015 Sep 07 Presented at: UbiComp '15: The 2015 ACM International Joint Conference on Pervasive and Ubiquitous Computing; 2015; Osaka, Japan. [doi: 10.1145/2802083.2802086]

12. Drummond D, Arnaud C, Guedj R, Duguet A, de Suremain N, Petit A. Google Glass for residents dealing with pediatric cardiopulmonary arrest: a randomized, controlled, simulation-based study. Pediatr Crit Care Med 2017 Feb;18(2):120-127. [doi: 10.1097/PCC.0000000000000977] [Medline: 28165347]

13. Siebert JN, Ehrler F, Gervaix A, Haddad K, Lacroix L, Schrurs P, et al. Adherence to AHA guidelines when adapted for augmented reality glasses for assisted pediatric cardiopulmonary resuscitation: a randomized controlled trial. J Med Internet Res 2017 May 29;19(5):e183 [FREE Full text] [doi: 10.2196/jmir.7379] [Medline: 28554878]

14. Designing calm technology. Weiser M, Brown JS. 1995. URL: https://calmtech.com/papers/designing-calm-technology. $\underline{\mathrm{html}}$ [accessed 2021-05-04]

15. Merchant RM, Topjian AA, Panchal AR, Cheng A, Aziz K, Berg KM, et al. Part 1: Executive Summary: 2020 American Heart Association Guidelines for Cardiopulmonary Resuscitation and Emergency Cardiovascular Care. Circulation 2020 Oct 20;142(16_suppl_2):337-357. [doi: 10.1161/cir.0000000000000918]

16. Maconochie IK, Bingham R, Eich C, López-Herce J, Rodríguez-Núñez A, Rajka T, Paediatric life support section Collaborators. European Resuscitation Council Guidelines for Resuscitation 2015: Section 6. Paediatric life support. Resuscitation 2015 Oct;95:223-248. [doi: 10.1016/j.resuscitation.2015.07.028] [Medline: 26477414]

17. Schmucker M, Igel C, Haag M. Evaluation of depth cameras for use as an augmented reality emergency ruler. Stud Health Technol Inform 2019;260:17-24. [Medline: 31118314]

18. Banker S. PediCalc medical app, customizable pediatric drug dosing at the touch of a button. iMedical Apps. URL: https:/ /www.imedicalapps.com/2012/02/pedicalc-medical-app-pediatric-drug-dosing/\# [accessed 2021-05-04]

19. Paediatricks. URL: http://paediatricks.com/peadiatrics [accessed 2021-05-04]

20. Pedi Safe. iAnesthesia LLC. URL: https://ianesthesia.org/apps/pedi-safe/ [accessed 2021-05-04]

21. Wetzel O, Schmidt AR, Seiler M, Scaramuzza D, Seifert B, Spahn DR, et al. A smartphone application to determine body length for body weight estimation in children: a prospective clinical trial. J Clin Monit Comput 2018 Jun;32(3):571-578. [doi: 10.1007/s10877-017-0041-z] [Medline: 28660564]

22. Corazza F, Snijders D, Arpone M, Stritoni V, Martinolli F, Daverio M, et al. Development and usability of a novel interactive tablet app (PediAppRREST) to support the management of pediatric cardiac arrest: pilot high-fidelity simulation-based study. JMIR Mhealth Uhealth 2020 Oct 01;8(10):e19070 [FREE Full text] [doi: 10.2196/19070] [Medline: $\underline{\text { 32788142] }}$

23. Siebert JN, Lacroix L, Cantais A, Manzano S, Ehrler F. The impact of a tablet app on adherence to American Heart Association guidelines during simulated pediatric cardiopulmonary resuscitation: randomized controlled trial. J Med Internet Res 2020 May 27;22(5):e17792 [FREE Full text] [doi: 10.2196/17792] [Medline: 32292179]

24. Siebert JN, Ehrler F, Combescure C, Lacroix L, Haddad K, Sanchez O, et al. A mobile device app to reduce time to drug delivery and medication errors during simulated pediatric cardiopulmonary resuscitation: a randomized controlled trial. J Med Internet Res 2017 Feb 01;19(2):e31 [FREE Full text] [doi: 10.2196/jmir.7005] [Medline: 28148473]

25. KiGGS: Studie zur Gesundheit von Kindern und Jugendlichen in Deutschland. Robert Koch Institut. URL: https://www. kiggs-studie.de/english/home.html [accessed 2021-05-04]

26. GitHub. TensorFlow Object Detection API. URL: https://github.com/tensorflow/models/tree/master/research/object detection [accessed 2021-05-11]

27. GitHub. TensorFlow 2 Detection Model Zoo. URL: https://github.com/tensorflow/models/blob/master/research/ object detection/g3doc/tf2 detection zoo.md [accessed 2021-05-11] 
28. Hale J. Deep learning power scores 2018. towards data science. URL: https://towardsdatascience.com/deep-learningframework-power-scores-2018-23607ddf297a [accessed 2021-05-11]

29. Build the future. Google ARCore. URL: https://developers.google.com/ar [accessed 2021-05-11]

30. Pediatape. URL: http://www.pediatape.com/ [accessed 2021-05-04]

31. Altman DG, Bland JM. Measurement in medicine: the analysis of method comparison studies. Statistician 1983 Sep;32(3):307. [doi: $10.2307 / 2987937]$

32. Bland JM, Altman DG. Statistical methods for assessing agreement between two methods of clinical measurement. Lancet 1986 Feb 8;1(8476):307-310. [Medline: 2868172]

33. Kromeyer-Hauschild K, Wabitsch M, Kunze D, Geller F, Geiß HC, Hesse V, et al. Perzentile für den Body-mass-Index für das Kindes- und Jugendalter unter Heranziehung verschiedener deutscher Stichproben. Monatsschrift Kinderheilkunde 2001 Aug 1;149(8):807-818. [doi: 10.1007/s001120170107]

34. Pluta W. Google stellt Project Tango ein. Golem. URL: https://www.golem.de/news/augmented-reality-google-stellt-projecttango-ein-1712-131709.html [accessed 2021-05-04]

35. Project Tango Java API example projects. GitHub. URL: https://github.com/googlearchive/tango-examples-java [accessed 2021-05-04]

36. Hübner P, Clintworth K, Liu Q, Weinmann M, Wursthorn S. Evaluation of HoloLens tracking and depth sensing for indoor mapping applications. Sensors (Basel) 2020 Feb 14;20(4):1021 [FREE Full text] [doi: 10.3390/s20041021] [Medline: $\underline{32074980]}$

37. What is DepthVision camera and how do you use it? Samsung. URL: https://www.samsung.com/global/galaxy/what-is/ 3d-depth-camera/ [accessed 2021-05-04]

38. iPhone 12 Pro and iPhone 12 Pro Max. Apple. URL: https://www.apple.com/iphone-12-pro/ [accessed 2021-05-04]

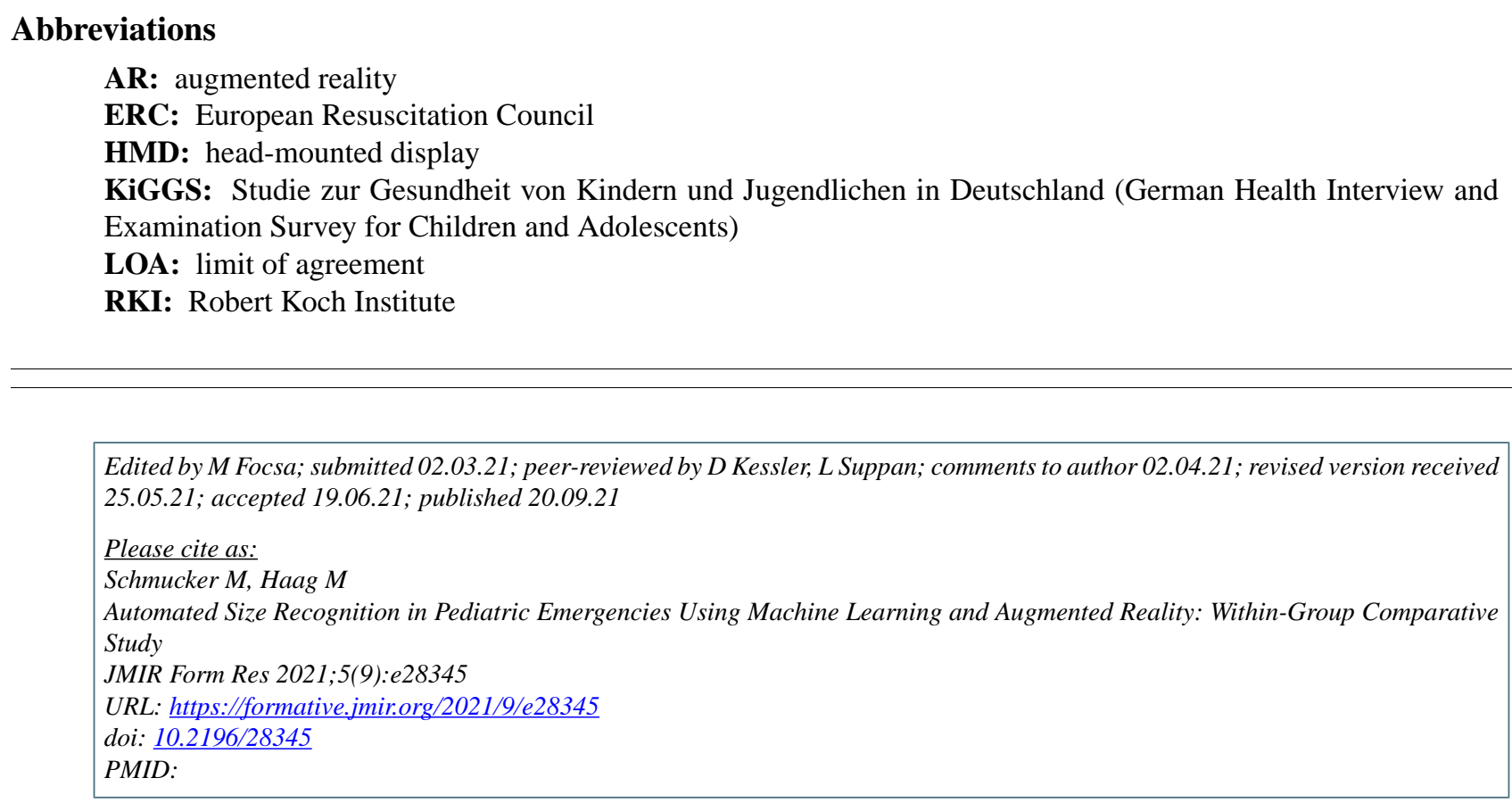

(CMichael Schmucker, Martin Haag. Originally published in JMIR Formative Research (https://formative.jmir.org), 20.09.2021. This is an open-access article distributed under the terms of the Creative Commons Attribution License (https://creativecommons.org/licenses/by/4.0/), which permits unrestricted use, distribution, and reproduction in any medium, provided the original work, first published in JMIR Formative Research, is properly cited. The complete bibliographic information, a link to the original publication on https://formative.jmir.org, as well as this copyright and license information must be included. 